\title{
Developing mobility as a service - user, operator and governance perspectives
}

\author{
Heikki Liimatainen ${ }^{1 *}$ and Miloš N. Mladenović ${ }^{2}$
}

Mobility as a Service (MaaS) can be briefly described as an emerging concept that aims to fulfil individual's mobility needs in a sustainable way by combining different transport services to seamless trips [1], offering an appealing alternative to owning and using a private car [2]. The core characteristics of MaaS include integration of multiple transport modes, various payment options, and use of various technologies enabling the use of single interface and platform, while catering for personalization and customization to offer user-centric mobility services [3]. The history of MaaS by name is not long, but MaaS can be seen as an evolutionary continuation of integrating mobility services [2], having its origins in Intelligent Transport Systems concepts [4]. In addition, these integration and customization efforts enabled by wider digitalization are related to many collaboration opportunities and challenges across diverse sets of actors in the mobility sector and beyond.

As we are witnessing MaaS emergence across the world, research on MaaS is accumulating rapidly [5-8]. Under the umbrella of an emerging concept, we can see that MaaS concept is evolving, as the technological aspects are changing simultaneously with the societal understanding of the underlying problems and needs. Thus, we are witnessing a phase of interpretative flexibility [9], where many actors have a surface agreement on MaaS conceptualization, but in fact have underlying conflicting perspectives. Similarly, previous research on MaaS has been quite diverse, ranging from studies of user perspectives and bundling design $[10,11]$, potential systemic effects such as welfare losses [12], as well as challenges of networked governance [13] and the need for responsible innovation practices [4].

This topical collection aims to provide additional breadth and depth to the rapidly developing MaaS

\footnotetext{
* Correspondence: heikki.liimatainen@tuni.fi

${ }^{1}$ Tampere University, Tampere, Finland

Full list of author information is available at the end of the article
}

literature. The papers can be clustered around three main themes. Firstly, three papers provide an overview of the state of MaaS development and discuss governance issues [14-16]. Secondly, three papers provide pilot and survey results with a focus on rural, urban and work-related mobility [17-19]. Thirdly, there are four papers which explore including new mobility offerings, in particular ridesourcing and automated transport, into mobility services [20-23].

\section{State of MaaS development and governance issues}

Esztergar-Kiss et al. [14] analyze the features of more than $30 \mathrm{MaaS}$ services and identify three cluster groups, of which the route planners usually include few transport modes but lack payment solutions, while the public systems include payments for public transport but have limited information on other modes. The third parties have most diverse services, including comprehensive mobility packages. Esztergar-Kiss et al. [14] and Murati [15] both highlight the importance of opening access to information and payment data services of transport operators for third-party resale and use. Such regulation already exists in Finland and France. However, providing comprehensive mobility packages encounters various governance issues. Murati [15] notes that there is no harmonised legal base for multimodal travel chains. Thus, passenger rights cannot be guaranteed on events delaying one segment of the journey and causing the passenger to miss the following segment. Hence, it is necessary to amend transport regulations from a multimodal perspective.

Van den Hurk et al. [16] identify through a case study in Utrecht responsibilities for public and private actors in cities to develop digital mobility platforms. They identify open questions about the roles of stakeholders, ambiguous understanding of the mobility platform and highlight the need for public and landowner 
participation in the development process to enable market-based demand for MaaS in cities.

\section{MaaS pilots and surveys}

Eckhardt et al. [17] widen the traditionally city-based scope of MaaS pilots and research to rural areas through two case studies in Finland. This research presents a demand-responsive transport pilot in Finland aimed to combine self-paying customers with government subsidized statutory social and health service transport customers. Based on the comprehensive key performance indicators, the integration may result in cost savings for public sector, improve vehicle occupancy rates and reduce vehicle mileage and emissions.

Maas [18] confirms the previous findings on the importance of public transport as the backbone of MaaS offerings and highlight car and bike sharing as enhancing the overall utility. His study from Dresden shows significant differences in the preferred type of subscription and shows a method for segmenting user groups. He also finds that private car costs are massively underestimated, which leads to prices for MaaS offerings to be considered too high. Günther et al. [19] conducted a 22month study with 93 university employees on corporate mobility as a service (CMaaS) and show that experiences of electric vehicles and mobility services on business travel may help to positively influence users' attitudes towards new mobility concepts. Integrated in-company multimodal mobility offerings also enable possibility of significant reductions in mobility costs for the business travel.

\section{New mobility services for MaaS}

In order to analyze the effects of mobility services on transport systems, it is necessary to incorporate travel chains into travel demand models. Wilkes et al. [20] show how ridesourcing services can be simulated in a microscopic travel demand model. They highlight that decision parameters for ridesourcing may differ from those for public transport and more data on willingness to pay and travel times is needed to improve the modelling. One solution for future last-mile service within MaaS offerings may be shared automated vehicles, which, according to Eppenberger \& Richter [21], may improve equity in accessibility if the complementarity to public transport is ensured. Bellone et al. [22] report the results of user surveys conducted during automated vehicle pilots in four cities. Overall experience of the automated minibuses were very positive and passengers felt safe on-board. However, increased speed, improved service level and smoother operation were commonly wished for future services. Automated vehicle pilots have mostly focused on minibuses, but Hang Rong et al. [23] present an analysis of waterborne automated vehicle services to visit museums in Amsterdam. Waterborne automated services would somewhat increase the total travel time compared to land public transport, but significantly decrease the walking distance. Survey results highlight that waterborne automated service could be preferred over land transport and traditional canal boats.

\section{Future research directions}

Presenting the papers together in this topical collection has the added value of giving the readers a wide understanding on the complex set of issues related to MaaS, while also giving specific examples from case studies. Given that developing MaaS is intertwined with the development of sustainable transport system as a whole, including specifically public transport system and new forms of micro-mobility together with the challenges of digitalisation, the papers of this topical collection are relevant to European transport researchers, practitioners, and policymakers.

Research collected under the banner of this topical collection has pushed the boundary of our understanding of MaaS, but also opened up new and highlighted old pathways for further research and development. To begin, we need further evaluation of various MaaS design variations, with or without bundling, in both stated preference and in living lab settings. This pathway goes hand in hand with longer pilot duration and higher emphasis on responsible innovation principles. For example, wider citizen engagement in pilots would help with expanding sample sizes and their representativeness by moving away from participants that are by default interested in new technologies. More responsible experimentation would also deploy mixed methods besides using only questionnaires, relying on focus group and even more engaging, co-creation and service design, methods. Furthermore, evaluation frameworks used in the future would need to expand to include a wider set of sustainability indicators. Simultaneously, as MaaS is emerging over time, we need further studies evaluating business models and market constellations as services and actors are evolving. For this aspect, we also need further governance studies, both in-depth cases and cross-comparison, accounting for diverse and changing networks of actors in operations, planning and policy. Finally, there is a further need for legislative studies on user rights and operator responsibilities, but also more fundamental studies on ethical principles for the ongoing digitalization of mobility services. With this in mind, we hope that this topical collection is an encouragement for researchers, practitioners, and policymakers to continue seeking future MaaS development pathways that are in line with a rich diversity of European cultures, and being grounded in European values of human dignity, equality, freedom and democracy. 


\section{Authors' contributions}

The authors read and approved the final manuscript.

\section{Declarations}

\section{Competing interests}

The authors declare no competing interests.

\section{Author details}

${ }^{1}$ Tampere University, Tampere, Finland. ${ }^{2}$ Aalto University, Espoo, Finland.

Received: 27 May 2021 Accepted: 3 June 2021

Published online: 23 June 2021

\section{References}

1. Utriainen, R., \& Pöllänen, M. (2018). Review on mobility as a service in scientific publications. Research in Transportation Business \& Management, 27, 15-23. https://doi.org/10.1016/j.rtbm.2018.10.005.

2. Lyons, G., Hammond, P., \& Mackay, K. (2019). The importance of user perspective in the evolution of MaaS. Transportation Research Part A: Policy and Practice, 121, 22-36.

3. Jittrapirom, P., Caiati, V., Feneri, A. M., Ebrahimigharehbaghi, S., Alonso González, M. J., \& Narayan, J. (2017). Mobility as a service: A critical review of definitions, assessments of schemes, and key challenges. Urban Planning, 2(2), 13-25. https://doi.org/10.17645/up.v2i2.931.

4. Pangbourne, K., Mladenović, M. N., Stead, D., \& Milakis, D. (2020). Questioning mobility as a service: Unanticipated implications for society and governance. Transportation research part A: policy and practice, 131, 3549.

5. Liimatainen, H., \& Mladenović, M. N. (2018). Understanding the complexity of mobility as a service. Research in Transportation Business and Management, 27, 1-2. https://doi.org/10.1016/j.rtbm.2018.12.004.

6. Amaral, A. M., Barreto, L., Baltazar, S., Silva, J. P., \& Gonçalves, L. (Eds.) (2019). Implications of mobility as a service (MaaS) in urban and rural environments: Emerging research and opportunities: Emerging research and opportunities. |GI global. Hershey: USA.

7. Hensher, D. A., \& Mulley, C. (2020). Special issue on developments in mobility as a service (MaaS) and intelligent mobility. Transportation Research Part A: Policy and Practice, 131, 1-4.

8. Hensher, D. A., Mulley, C., Ho, C., Smith, G., Wong, Y., \& Nelson, J. D. (2020), Understanding mobility as a service (Maas): Past, present and future. Amsterdam: Elsevier.

9. Mladenović, M. N., \& Haavisto, N. (2021). Interpretative flexibility and conflicts in the emergence of mobility as a service: Finnish public sector actor perspectives. Case Studies on Transport Policy.

10. Liljamo, T., Liimatainen, H., Pöllänen, M., \& Utriainen, R. (2020). People's current mobility costs and willingness to pay for mobility as a service offerings. Transp Res A Policy Pract, 136, 99-119.

11. Hensher, D. A., Ho, C. Q., \& Reck, D. J. (2021). Mobility as a service and private car use: Evidence from the Sydney MaaS trial. Transportation Research Part A: Policy and Practice, 145, 17-33.

12. Hörcher, D., \& Graham, D. J. (2020). MaaS economics: Should we fight car ownership with subscriptions to alternative modes? Economics of Transportation, 22, 100167. https://doi.org/10.1016/j.ecotra.2020.100167.

13. Smith, G., Sochor, J., \& Karlsson, I. M. (2020). Intermediary MaaS integrators: A case study on hopes and fears. Transportation Research Part A: Policy and Practice, 131, 163-177.

14. Esztergar-Kiss, D., Kerenyi, T., Matrai, T., \& Aba, A. (2020). Exploring the MaaS market with systematic analysis. European Transport Research Review, 12(1), 67. https://doi.org/10.1186/s12544-020-00465-z.

15. Murati, E. (2020). Mobility -as-a-service (MaaS) digital marketplace impact on EU passengers' rights. European Transport Research Review, 12(1), 62. https:// doi.org/10.1186/s12544-020-00447-1.

16. Van den Hurk, M., Pelzer, P., \& Riemens, R. (2021). Governance challenges of mobility platforms: The case of Merwede, Utrecht. European Transport Research Review, 13(1), 23. https://doi.org/10.1186/s12544-021-00483-5.

17. Eckhardt, J., Lauhkonen, A., \& Aapaoja, A. (2020). Impact assessment of rural PPP MaaS pilots. European Transport Research Review, 12(1), 49. https://doi. org/10.1186/s12544-020-00443-5.
18. Maas, B. (2021). Conjoint analysis of mobility plans in the city of Dresden. European Transport Research Review, 13(1), 25. https://doi.org/10.1186/s12 544-021-00478-2.

19. Günther, M., Jacobsen, B., Rehme, M., Götze, U., \& Krems, J. F. (2020). Understanding user attitudes and economic aspects in a corporate multimodal mobility system: Results from a field study in Germany. European Transport Research Review, 12(1), 64. https://doi.org/10.1186/s12 544-020-00456-0.

20. Wilkes, G., Briem, L., Heilig, M., Hilgert, T., Kagerbauer, M., \& Vortisch, P. (2021). Determining service provider and transport system related effects of ridesourcing services by simulation within the travel demand model mobiTopp. European Transport Research Review, 13(1), 34. https://doi.org/1 0.1186/s12544-021-00493-3.

21. Eppenberger, N., \& Richter, M. A. (2021). The opportunity of shared autonomous vehicles to improve spatial equity in accessibility and socioeconomic developments in European urban areas. European Transport Research Review, 13(1), 32. https://doi.org/10.1186/s12544-021-00484-4.

22. Bellone, M., Ismailogullari, A., Kantala, T., Mäkinen, S., Soe, R.-M., \& Åman Kyyrö, M. (2021). A cross-country comparison of user experience of public autonomous transport. European Transport Research Review, 13(1), 19. https://doi.org/10.1186/s12544-021-00477-3.

23. Hang Rong, H., Tu, W., Duarte, F., \& Ratti, C. (2020). Employing waterborne autonomous vehicles for museum visits: A case study in Amsterdam. European Transport Research Review, 12(1), 63. https://doi.org/10.1186/s12 544-020-00459-X.

\section{Publisher's Note}

Springer Nature remains neutral with regard to jurisdictional claims in published maps and institutional affiliations.

\section{Submit your manuscript to a SpringerOpen ${ }^{\circ}$ journal and benefit from:}

- Convenient online submission

- Rigorous peer review

- Open access: articles freely available online

- High visibility within the field

- Retaining the copyright to your article

Submit your next manuscript at $\boldsymbol{\nabla}$ springeropen.com 